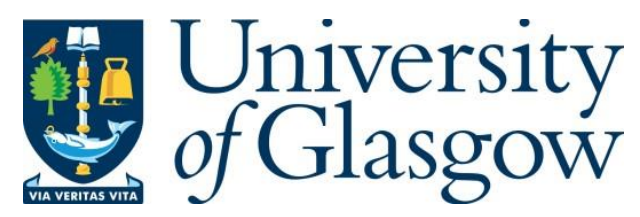

Wood, J. D., Gauvin, C., Young, C. R.T., Taylor, A. C., Balint, D. S. and

Charalambides, M. N. (2019) Reconstruction of historical temperature and relative

humidity cycles within Knole House, Kent. Journal of Cultural Heritage, 39, pp. 212220.

There may be differences between this version and the published version. You are advised to consult the publisher's version if you wish to cite from it.

$\underline{\text { http://eprints.gla.ac.uk/189196/ }}$

Deposited on: 23 February 2021

Enlighten - Research publications by members of the University of Glasgow http://eprints.gla.ac.uk 


\title{
Reconstruction of historical temperature and relative humidity cycles within Knole House, Kent
}

\author{
J.D. Wood ${ }^{\mathrm{a}, *}$, C. Gauvin ${ }^{\mathrm{b}}$, C.R.T. Young ${ }^{\mathrm{b}}$, A.C. Taylor ${ }^{\mathrm{a}}$, D.S. Balint ${ }^{\mathrm{a}}$, M.N. Charalambides ${ }^{\mathrm{a}}$ \\ a. Department of Mechanical Engineering, Imperial College London, London, SW7 2AZ, UK. \\ b. School of Culture \& Creative Arts, College of Arts, University of Glasgow, Glasgow, G12 8QQ, UK. \\ Length of manuscript: 7772 words.
}

\begin{abstract}
It is essential for the preservation of cultural heritage that the effects of climate change are investigated. With this in mind, the daily temperature and relative humidity $(\mathrm{RH})$ cycles within the Brown Gallery at Knole House, Kent, have been reconstructed for the period 1605 - 2015 enabling the study of low-cycle environmental fatigue on a set of $17^{\text {th }}$ century panel paintings. By establishing a relationship between the temperature in the Brown Gallery and the Hadley Centre Central England Temperature (HadCET) dataset over a sixteen year period $(2000-2015)$, it is possible to use the full HadCET dataset to obtain the daily minimum and maximum temperatures in the Brown Gallery for the period 1878 - 2015. Using a Fourier series to fit the periodic data it is then possible to extrapolate back to 1605 . Furthermore, correction factors derived using the HadCET average daily temperature in the period 1772 - 1877 and average monthly temperature in the period 1659 - 1771 are applied to the temperature data to increase the model accuracy. The daily minimum and maximum RH for the period 1605 - 2015 are obtained using the Brown Gallery maximum and minimum temperatures respectively, and assuming that the daily dew point temperature at Knole is calculated by subtracting a monthly-dependent constant from the daily minimum temperature at Knole, thus enabling the calculation of the daily actual water vapour pressure of air. Changes in RH are a result of the daily temperature cycle changing the saturation vapour pressure of air in the gallery. This data is valuable as it enables a study of the effects of low-cycle fatigue on the $17^{\text {th }}$ century panel paintings housed in the Brown Gallery at Knole House, Kent due to these temperature and relative humidity cycles. Furthermore, the method presented offers a technique that can be utilised to replicate the internal environment for any unheated monument building so that the effects of past and future temperature and humidity cycles on cultural heritage can be examined.
\end{abstract}

\footnotetext{
* Corresponding Author
}

Email address:

joseph.wood@imperial.ac.uk (J.D. Wood) m. charalambides@imperial.ac.uk (M.N. Charalambides) 
Keywords: Fourier transform; Historic environment; Knole House; Panel paintings; Temperature and relative humidity cycles.

\section{Introduction}

At Knole House, Kent a set of forty three portraits, executed on panel, are displayed in the Brown Gallery. Dendrochronology has been performed on sixty-five boards from twenty-two of the panels confirming that the paintings were executed on Baltic oak no earlier than 1605, further technical and contextual analysis show that the paintings were completed in the early decades of the $17^{\text {th }}$ Century [1]. Knole House provides a rare opportunity to study the effects of temperature and humidity on panel paintings as there currently is no means of modern heating within this part of the building and the portrait set has been displayed together for over four hundred years, firstly in the Cartoon Gallery, and then probably from 1700, in the Brown Gallery at Knole House. This means that the majority of the paintings have been exposed to the same cyclic temperature and moisture changes (with a few having short times away from Knole for exhibitions and conservation treatments) which correlate with atmospheric conditions outside the House, locally at Knole, Kent.

It is advantageous to have a model that calculates the temperature and relative humidity $(\mathrm{RH})$ that the paintings have been exposed to from their original display at Knole (approx. 1605) to 2015 when the paintings were removed from the gallery and placed in temporary storage in a semicontrolled environment. Such information is key to investigating the effects of environmentallyinduced fatigue on cracking and delamination in panel paintings through the use of finite-elementbased models [2]. This paper presents the method that has been used to extrapolate the temperature and relative humidity (RH) cycles in the Brown Gallery back to 1605. Furthermore, the method can be utilised for any unheated building to aid in the study of the effects of the environment on a variety of cultural heritage.

The panel paintings are typical of an early Northern European construction with an oak panel sized with animal glue, a chalk and lead white ground layer, and pigmented layers bound in a drying oil. Due to changes in temperature and humidity, the organic and polymeric materials in paintings can experience strain differentials between layers as a result of the mismatch in hygrothermal properties [3]. These strain differentials, caused by changes in temperature and humidity, are considered to be the main cause of through-thickness cracks in the paint layer and delaminations along the paint layer interface [4]. Such cracking and delamination result in loss of paint, and a consequent loss of the aesthetic of the work, interpretation and appreciation by the viewer. The cyclic nature of $\mathrm{RH}$ has been shown and the effect of these cycles with varying 
fluctuation frequencies on the moisture penetration of oak wood examined [5]. Therefore, for collections in uncontrolled and controlled environments, both which have cyclic RH variations, it is important to investigate the cyclic behaviour that could be one cause of damage as a result of environmentally-induced fatigue. Predicting fatigue life-times as a function of environmental cycling is imperative in order to best preserve painted wooden cultural heritage for future generations.

Previous related work on environmental modelling of an unheated room include Lankester and Brimblecombe [6], [7] where temperature and RH were obtained and then extrapolated for the period 1860 - 2099. Furthermore, data from the Met Office Hadley Centre Central England Temperature extended the period back to 1770 [8]. A transfer function for each month of the year, based on nine years of data, related the outside conditions to that inside the Leicester Gallery and Cartoon Gallery at Knole House, Kent. Although both galleries are of similar design and located in the same building, it was shown that the internal environment can be very different. Unfortunately, due to the simplicity of the model, errors of up to $\pm 2{ }^{\circ} \mathrm{C}$ and $\pm 10 \% \mathrm{RH}$ were apparent when compared to data recordings. Developing the model by using transfer functions calibrated with temperature and $\mathrm{RH}$ readings over a greater period of time may mitigate these errors.

Other studies have been performed using transfer functions to obtain indoor conditions from outside, showing the validity of this simple method. Bratasz et al. [9] combined the transfer functions with a future climate model to obtain the environmental conditions in an unheated room and identify a climatological risk index showing areas of Europe where paintings on wood would be most susceptible to climate change. Camuffo et al. [10] applied the concept with proxy data $(1500-1715)$ and instrument readings $(1716$ - 2009) to reconstruct the historical climate in the Cathedral of Cremona, Lombardy, Italy. In some instances it was not possible to obtain simultaneous readings for indoor and outdoor conditions and thus under these circumstances readings for similar buildings within the same climatic region were used, potentially introducing errors into the model. Bertolin et al. [11] applied the same method to the basilica of S. Giustina, Padua, Italy.

Kramer et al. [12] developed simple hygrothermal models to obtain the indoor environment of monument buildings. Model calibration was achieved through optimisation that minimised the error between measurements in the room and the model output. The study showed that the simple hygrothermal model was able to produce accurate results for the indoor environment.

Examples of more complex methods to obtain a building indoor environment from outside include the Climate for Culture [13] project, where a full building hygrothermal simulation was 
used in combination with computational fluid dynamics to analyse the flow of air in the rooms. An advantage of a full building simulation over the use of a transfer function is that the type of building use and heating, ventilation and air conditioning can all be accounted for in the model, however there are high development and computational costs. Leijonhufvud [14] applied these results to assess the future indoor risks to Swedish churches. Further use of a hygrothermal building simulation enabled Huijbregts et al. [15] to take building properties and user behaviour into account when reconstructing the past climate in a $17^{\text {th }}$ century Dutch castle using meteorological data.

The transfer function method utilised in this work has been shown to give accurate results for an unheated room [6], [7], [9]-[11], [13] and it does not have high development/computational costs associated with a full building hygrothermal simulation. The work in this paper makes use of the Met Office Hadley Centre Central England Temperature (HadCET) [16] data. Hourly temperature and RH readings collected by The Courtauld Institute of Art and The National Trust [17] inside two galleries at Knole House (Brown Gallery and Cartoon Gallery) and outside the house over a sixteen year period $(2000-2015)$ are also used. The HadCET dataset contains the longest record of temperature recordings in the world. These daily and monthly temperatures are representative of a roughly triangular area enclosed by Lancashire, London and Bristol, UK.

Although the environmental conditions in the Leicester and Cartoon galleries at Knole House have previously been studied using transfer functions to relate the outside conditions to those inside [6][8], this work offers a novel contribution as the Brown Gallery has not been considered before and the paintings provide a unique epidemiological case study. Furthermore, an original method is presented to reproduce the past temperature and RH cycles back to 1605 in the gallery. Finally the work is key in the study of environmental effects on $17^{\text {th }}$ century panel paintings as it provides the required boundary conditions to develop a finite element model to investigate fracture due to environmentally-induced low-cycle fatigue. The method presented is not restricted to the Brown Gallery and has a greater application to reconstruct the temperature and humidity cycles in other unheated buildings based on proxy data. If temperature and humidity data is available for both inside and outside an unheated room, then the past or future climate in the room can be obtained from outside using proxy data or a future climate model, respectively. This enables the study of environmental effects on the items housed within the room and consequently the potential for damage of unique cultural heritage can be investigated. 


\section{Research aim}

The main aim of the research was to determine the past temperature and relative humidity cycles present in the Brown Gallery, Knole House, Kent, during the period 1605 - 2015. This particular period is of interest as the panel paintings have been on display for over four hundred years with no modern form of heating. By recreating the environmental conditions that the paintings have been subjected to, it is possible to study the effects of low-cycle fatigue due to changes in temperature and relative humidity and its impact on the formation of crack damage in paintings. Furthermore, the method to reconstruct the environment in an unheated building can be replicated to investigate the effects of building internal environment on damage initiation in cultural heritage.

\section{Methodology}

\subsection{Temperature and relative humidity recordings}

Table 1 summaries the temperature and RH data that are available from which to extrapolate temperature and RH cycles that have occurred in the Brown Gallery for the period 1605-2015. Hourly temperature and $\mathrm{RH}$ data has an accuracy of $\pm 0.3^{\circ} \mathrm{C}$ and $\pm 3 \% \mathrm{RH}$, respectively. The Met Office Hadley Centre Central England Temperature (HadCET) [16] data do not quote the relative humidity. To date the authors have been unable to find suitable proxy data for the RH in Knole, with the earliest reading obtained in 2000 . However, daily precipitation data is available for Central England back to 1931, and monthly data back to 1873 .

Table 1: Temperature and relative humidity data available.

\begin{tabular}{|c|c|c|}
\hline Location & Temperature data & Relative humidity data \\
\hline Brown Gallery, Knole House, Kent & Hourly data $(2000-2015)$ & Hourly data $(2000-2015)$ \\
\hline Cartoon Gallery, Knole House, Kent & Hourly data $(2000-2015)$ & Hourly data $(2000-2015)$ \\
\hline Outside Knole House, Kent & Hourly data $(2000-2015)$ & Hourly data $(2000-2015)$ \\
\hline $\begin{array}{l}\text { Central England (region between } \\
\text { Bristol, Lancashire and London) }\end{array}$ & $\begin{array}{l}\text { HadCET daily minimum/maximum } \\
(1878-2015) \\
\text { HadCET daily average }(1772-2015) \\
\text { HadCET monthly average }(1659-2015)\end{array}$ & $\begin{array}{l}\text { Daily precipitation records (1931- } \\
2015) \\
\text { Monthly precipitation records (1873- } \\
2015)\end{array}$ \\
\hline
\end{tabular}

It is of interest to identify the main frequencies that the paintings in the Brown Gallery have been subjected to. As a result of the cyclic nature of the hourly temperature and humidity readings for the Brown Gallery, a Fourier transform can be performed on the data for the sixteen year period (2000 - 2015). Figure 1 shows the dominant amplitudes in the frequency spectrum for the temperature and RH data in the Brown Gallery over a sixteen year period $(2000-2015)$. 
(a) Temperature

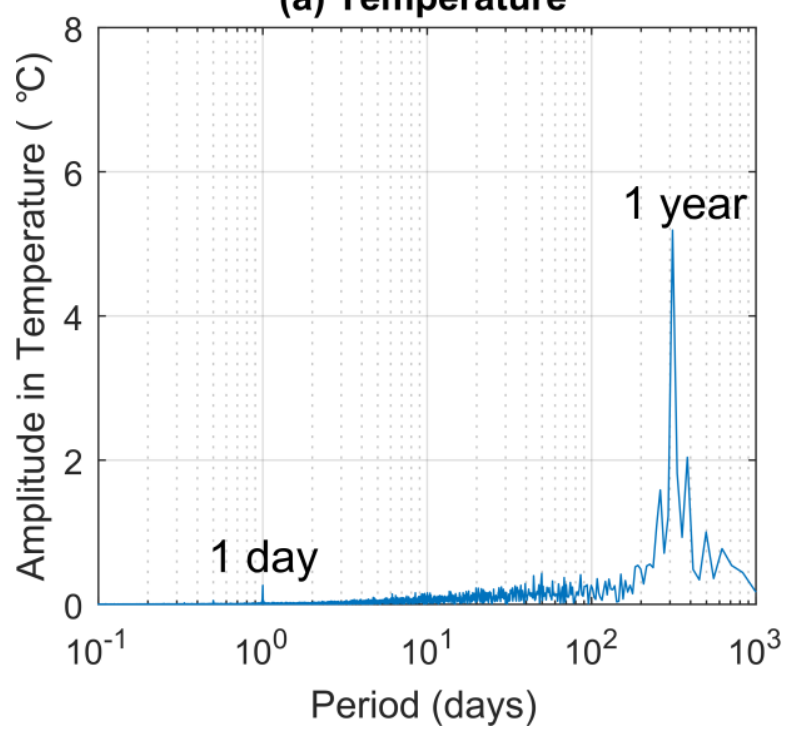

(b) Relative Humidity

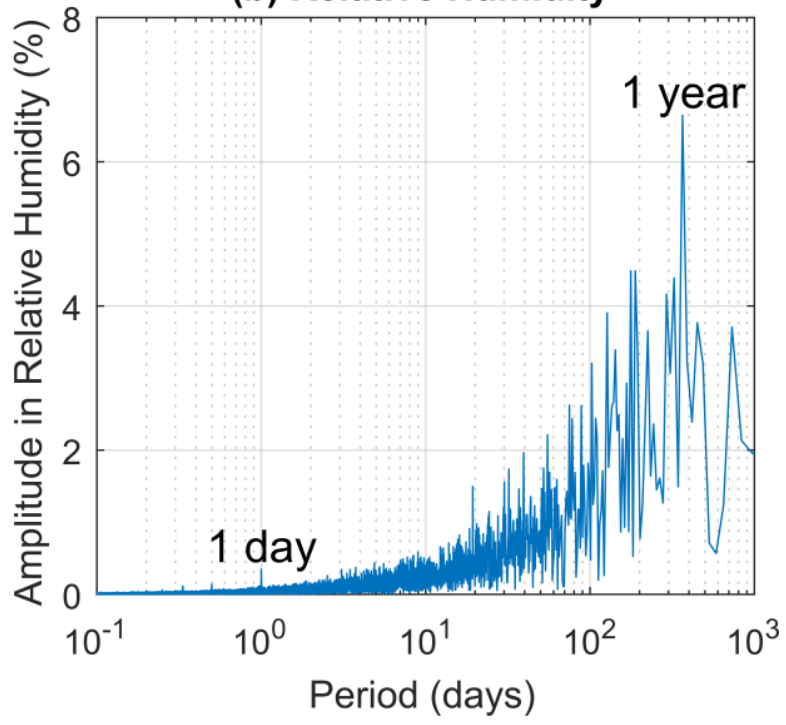

Figure 1: Frequency spectrum for the sixteen years (2000 - 2015) of Brown Gallery temperature and relative humidity data after Fourier transform (a) Temperature. (b) Relative humidity.

Figure 1 shows that there are dominant peaks in the amplitude for both temperature and $\mathrm{RH}$ corresponding to a period of one day and one year, as would be expected. Due to noise in the temperature data the amplitude peak in the frequency spectrum corresponding to one year is 54 days shorter than expected. There are also smaller peaks with periods of less than 1 day, and these correspond to six, eight and twelve hours. It is interesting to note that currently it is unknown whether these smaller amplitude, more frequent cycles in temperature and RH are more detrimental to the painting rather than the larger amplitude cycles over a longer time, especially when the constituent materials of the panel painting show a viscoelastic response and therefore stress relaxation. This question will be investigated in the future through the use of mechanical fatigue testing and finite element modelling in order to identify which cycles are more damaging to the lifetime of the painting. Acoustic emission studies [18], [19] have provided some insight into the detrimental effects of relative humidity changes in an objects environment through the monitoring of ultrasound and sound waves released when damage occurs in a restrained wooden structure. For example, two years of in-situ testing of an eighteenth century wooden wardrobe identified that 1.2 $\mathrm{mm}$ of crack growth was evident due to decreases in indoor humidity in winter.

\subsection{Fill in gaps in data}

Hourly data for temperature and RH have been provided for a sixteen year period (2000 - 2015) for the Brown Gallery, Cartoon Gallery and outside Knole House. However, gaps appear when the data loggers have malfunctioned. Before establishing a relationship between the recordings in the 
Brown Gallery and Knole House exterior, the gaps in the data should be filled as more data points will yield more accurate transfer functions. For the majority of cases when the data logger malfunctioned in the Brown Gallery, the data logger in the Cartoon Gallery was still functioning normally. Therefore, the gaps in the Brown Gallery data can be filled by comparing the temperature (or relative humidity) in the Brown Gallery to that in the Cartoon Gallery and establishing a relationship. Comparing the hourly data for a given month over the sixteen year period, it is possible to establish twelve relationships of the form

$$
\begin{aligned}
\mathrm{T}_{\mathrm{BG}} & =\mathrm{a}_{\mathrm{i}} \mathrm{T}_{\mathrm{CG}}+\mathrm{b}_{\mathrm{i}} \\
\mathrm{RH}_{\mathrm{BG}} & =\mathrm{e}_{\mathrm{i}} \mathrm{RH}_{\mathrm{CG}}+\mathrm{g}_{\mathrm{i}}
\end{aligned}
$$

where $\mathrm{T}$ and RH are the hourly temperature and relative humidity in the gallery with subscript BG and CG referring to the Brown Gallery and Cartoon Gallery respectively. The variables $a_{i}, b_{i}, e_{i}$ and $g_{i}$ are fitting coefficients with $i=1-12$ corresponding to each month of the year (January December). Therefore, twelve sets of coefficients are obtained, one for each month. It is assumed that even with remodelling of the galleries, the majority of the building fabric has been unaltered over the 411 years from 1605 to 2015 [20], such that the relationship between the inside and outside conditions remains the same, meaning the coefficients remain constant for the period.

\subsection{Exterior temperature Knole House, Kent}

The past temperature data used in this work are from HadCET [16] for a triangle between Lancashire, London and Bristol. As Knole House in Kent is located outside of this region, these temperatures have been adjusted to represent the local temperature at Knole. As this relationship involves outdoor temperatures, only one transfer function is required, based on the daily average temperatures in Central England and outside Knole House, unlike the transfer function in Section 3.2 (and later in Section 3.4) which varies seasonally due to the sun heating the room. To achieve this, a similar approach to Section 3.2 is used to obtain a relationship in the form

$$
\overline{\mathrm{T}}_{\mathrm{KO}}=\mathrm{h} \overline{\mathrm{T}}_{\mathrm{CE}}+\mathrm{k}
$$

where $\overline{\mathrm{T}}$ is the daily average temperature with subscripts $\mathrm{KO}$ and CE corresponding to outside Knole House and Central England respectively, and $\mathrm{h}$ and $\mathrm{k}$ are fitting coefficients. With this relationship, the minimum and maximum temperatures in Central England can be converted to the minimum and maximum exterior temperatures at Knole House from 1878 - 2015. Furthermore, the relationship can also be used to convert the daily (1772 - 2015) and monthly (1659 - 2015) 
average temperatures in Central England to daily and monthly average temperatures outside Knole House for the same periods.

\subsection{Temperature inside Brown Gallery}

From literature [6], [7], [9]-[11], [13] it has been shown that a transfer function relating the inside temperature (or relative humidity) to that outside provides a quick and accurate way to predict the temperature inside an unheated room. The final relationship required to obtain the temperature from $1605-2015$ in the Brown Gallery is that between the temperature inside the Brown Gallery and exterior at Knole House. This is achieved by again plotting twelve graphs (one for each month) for the sixteen year period where hourly data is available for the Brown Gallery. Averaging the hourly data gives the daily average temperature inside the Brown Gallery $\left(\overline{\mathrm{T}}_{\mathrm{BG}}\right)$ and this is compared to the daily average temperature outside Knole House ( $\left.\overline{\mathrm{T}}_{\mathrm{KO}}\right)$ obtained from the daily average temperature in Central England $\left(\overline{\mathrm{T}}_{\mathrm{CE}}\right)$ and using Equation 3. The data can be fitted with a linear relationship of the form

$$
\overline{\mathrm{T}}_{\mathrm{BG}}=\mathrm{n}_{\mathrm{i}} \overline{\mathrm{T}}_{\mathrm{KO}}+\mathrm{p}_{\mathrm{i}}
$$

where $n_{i}$ and $p_{i}$ are fitting coefficients with $i=1-12$ depending on the month of the year. It is then possible to acquire the minimum and maximum temperatures in the Brown Gallery for the period 1878 - 2015 using the daily minimum and maximum temperatures from HadCET.

The daily minimum $\left(\breve{T}_{B G}\right)$ and daily maximum $\left(\widehat{T}_{B G}\right)$ temperatures in the Brown Gallery can be fitted with a Fourier series of the form

$$
\breve{\mathrm{T}}_{\mathrm{BG}}, \widehat{\mathrm{T}}_{\mathrm{BG}}=\mathrm{A}_{0}+\sum_{\mathrm{j}=1}^{\mathrm{N}} \mathrm{A}_{\mathrm{j}} \cos (\mathrm{jx})+\mathrm{B}_{\mathrm{j}} \sin (\mathrm{jx})
$$

where $\mathrm{N}$ is the number of terms in the Fourier series, enabling backwards extrapolation of these temperatures to 1605 . To increase the accuracy of the model in periods 1772 - 1877 and $1659-$ 1771 correction factors have been derived based on the daily average temperatures and monthly average temperatures from HadCET respectively. Details of the application of this method are given in Appendix A.

\subsection{Relative humidity inside Brown Gallery}

Due to the lack of relative humidity data over a long period prior to the year 2000 for both the Brown Gallery and outside at Knole House, a method is required to obtain the minimum and maximum daily RH. For a given temperature (T), the RH is defined as the percentage of actual water vapour pressure of air $\left(e_{a}\right)$ to the saturation vapour pressure of air $\left(e_{s}\right)$ 


$$
\mathrm{RH}=\frac{\mathrm{e}_{\mathrm{a}}(\mathrm{T})}{\mathrm{e}_{\mathrm{s}}(\mathrm{T})} \times 100
$$

The saturation vapour pressure of air $(\mathrm{kPa})$ at a given temperature $\mathrm{T}\left({ }^{\circ} \mathrm{C}\right)$ can be calculated using the following empirical formula [21]-[24]

$$
\mathrm{e}_{\mathrm{s}}=0.6108 \exp \left[\frac{(17.27 \mathrm{~T})}{\mathrm{T}+237.3}\right]
$$

The daily actual vapour pressure of air $(\mathrm{kPa})$ can be calculated using the saturation vapour pressure of air at the dew point temperature $\left(\mathrm{T}_{\mathrm{dew}}\right)$ [21]-[24], where the dew point temperature is defined as the temperature that the air needs to be cooled to in order to be fully saturated

$$
\mathrm{e}_{\mathrm{a}}=0.6108 \exp \left[\frac{\left(17.27 \mathrm{~T}_{\mathrm{dew}}\right)}{\mathrm{T}_{\mathrm{dew}}+237.3}\right]
$$

Therefore to calculate the minimum and maximum relative humidity, three temperatures are required. These are the minimum, maximum and dew point temperatures. Sections 3.3 and 3.4 state a method to obtain the minimum and maximum temperatures outside at Knole and inside the Brown Gallery. Therefore, the only temperature now required is the dew point temperature. Following previous work [21]-[24] on predicting the dew point temperature, it is assumed that early in the morning before sunrise, the air is almost fully saturated (i.e. $\mathrm{RH} \approx 100 \%$ ) so the dew point temperature is approximately the same as the daily minimum temperature outside at Knole $\left(\widetilde{\mathrm{T}}_{\mathrm{KO}}\right)$

$$
\mathrm{T}_{\mathrm{dew}} \approx \widetilde{\mathrm{T}}_{\mathrm{KO}}
$$

This can be confirmed using the temperature and relative humidity data at Knole by averaging the data for a given hour (e.g. 3:00 am) over the period 2000-2015, and then identifying at which hour the maximum average RH and minimum average temperature occurs. The maximum average relative humidity occur at 5:00 am (91\%) and 6:00 am (91\%) which also correspond to the two minimum average temperatures of $9.3^{\circ} \mathrm{C}$ and $9.4{ }^{\circ} \mathrm{C}$ respectively.

As the maximum average $\mathrm{RH}$ is $91 \%$, this indicates that the accuracy of the model can be further increased if the daily average dew point temperature is below the minimum temperature, and therefore a constant (v) can be subtracted from the minimum temperature. Different definitions of $\mathrm{v}$ include a constant for all data [21], [22], $\mathrm{v}_{\mathrm{i}}$ (with $\mathrm{i}=1-12$ ) calibrated for each month [22], [24] and finally incorporating precipitation records with the monthly definition of $v_{i}$ to include wet and dry days, where a wet day is defined as having a least $1 \mathrm{~mm}$ of rain [23]. In this work the monthly definition without using precipitation records will be utilised because daily precipitation records are only available for the period 1931 - 2015 and are not site-specific: 


$$
\mathrm{T}_{\mathrm{dew}}=\breve{\mathrm{T}}_{\mathrm{KO}}-\mathrm{v}_{\mathrm{i}}
$$

with $i=1-12$. The value of $v_{i}$ for each month is determined by minimising the error between the daily minimum and maximum $\mathrm{RH}$ values produced from the model and sensor data at Knole for the period $2000-2015$.

It has been shown in the USA [25] that on average when comparing the daily dew point temperature to the nightly value, there is a difference of $0.5^{\circ} \mathrm{C}$, suggesting that the absolute moisture content of air remains reasonably constant throughout a 24 hour period and changes in $\mathrm{RH}$ are a result of the temperature cycle modifying the saturation vapour pressure of air. This method has been utilised in other regions for example India [22], Italy [23] and Japan [24] and will now be applied to Knole, Kent, UK.

Calculating the daily actual vapour pressure of air using the dew point temperature, it is also assumed that the actual vapour pressure of air inside the unheated gallery is the same as outside Knole House. Therefore, the daily changes in RH in the Brown Gallery are due to the temperature cycle changing the saturation vapour pressure of the air, $\mathrm{e}_{\mathrm{s}}$. Thus the minimum and maximum $\mathrm{RH}$ can be calculated

$$
\begin{aligned}
& \widetilde{R H}=\frac{e_{a}}{e_{s}\left(\widehat{T}_{B G}\right)} \times 100 \\
& \widehat{R H}=\frac{e_{a}}{e_{s}\left(\widetilde{T}_{B G}\right)} \times 100
\end{aligned}
$$

This method enables the calculation of the daily minimum and maximum relative humidity in the Brown Gallery for the period $1605-2015$.

\section{Results}

\subsection{Fill in gaps in data}

Following the method given in Section 3.2, relationships between the temperatures in the Cartoon Gallery and Brown Gallery are obtained from the available data $(2000$ - 2015). Figure 2 compares the daily average temperature in the Brown Gallery from the data recordings to those using the Cartoon Gallery recordings with the method described in Section 3.2. Figure 2a shows the results for February 2008 which has the poorest correlation with $\mathrm{R}^{2}=0.62$. Figure $2 \mathrm{~b}$ shows the results for June 2009 which has the strongest correlation with $\mathrm{R}^{2}=0.98$. Averaging the values of $\mathrm{R}^{2}$ over all months gives $\mathrm{R}^{2}=0.82$, showing the validity of using the temperature in the Cartoon Gallery and linear relationship to fill the temperature data gaps. 
(a) February 2008

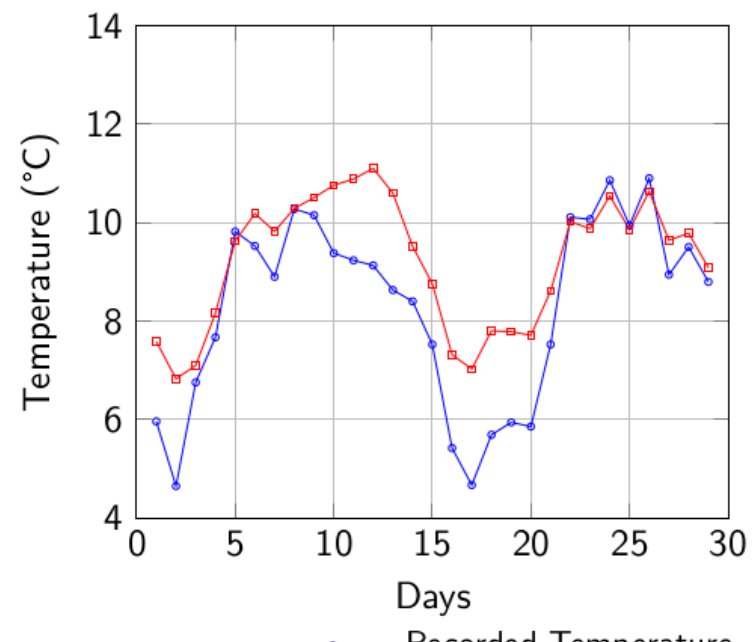

(b) June 2009

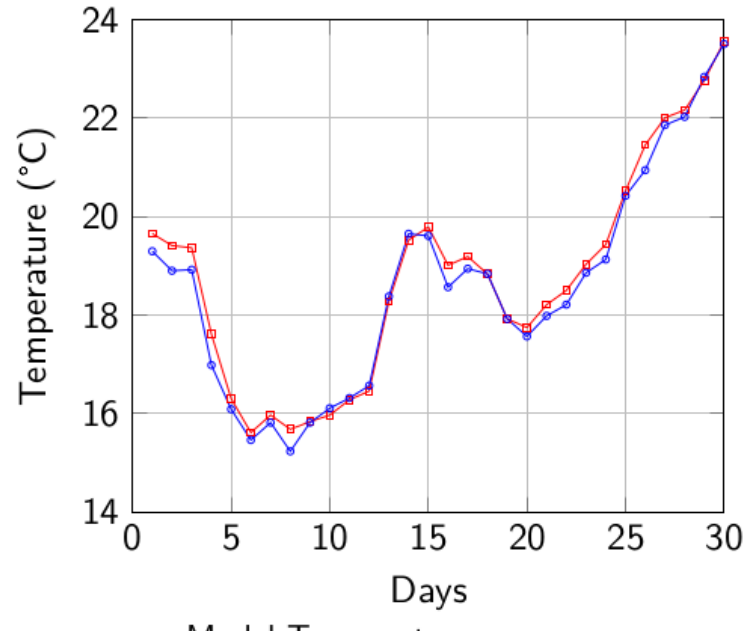

Figure 2: Comparison of daily average temperature in the Brown Gallery from recordings and using the linear relationship with the recorded Cartoon Gallery temperature. (a) February 2008.

(b) June 2009. The worst and best value of $\mathrm{R}^{2}$, respectively.

The coefficients for the monthly relationship between the Brown Gallery and Cartoon Gallery are given in Appendix B in Table B1.

\subsection{Exterior temperature Knole House, Kent}

Using the method outlined in Section 3.3, the temperatures from HadCET, $\overline{\mathrm{T}}_{\mathrm{CE}}$, are used to match those temperature outside at Knole House, $\overline{\mathrm{T}}_{\mathrm{KO}}$, via the linear relationship in Equation 3. Figure 3 shows the daily average temperature in Central England and the corresponding temperature outside Knole House for the period 2000 - 2015. Only days where there is a complete set of hourly data for outside Knole House have been used in the daily average temperature calculation. There is a strong correlation between the temperatures in Central England and those outside Knole House, and a linear fit to the data gives

$$
\overline{\mathrm{T}}_{\mathrm{KO}}=1.07 \overline{\mathrm{T}}_{\mathrm{CE}}+0.22
$$

and $\mathrm{R}^{2}=0.92$ 


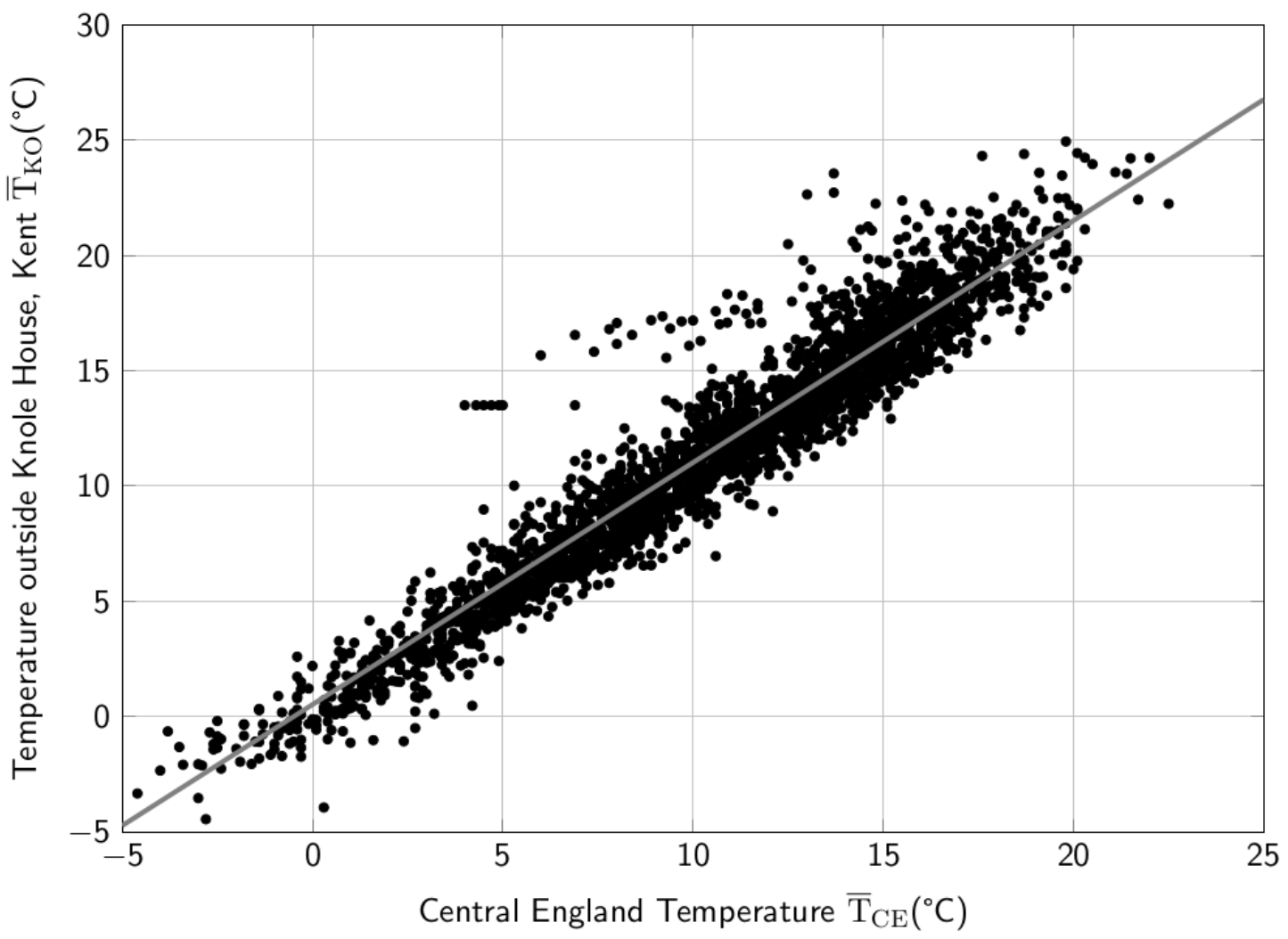

Figure 3: Relationship between the daily average temperatures in Central England $\left(\overline{\mathrm{T}}_{\mathrm{CE}}\right)$ provided by HadCET [16] and recordings outside Knole House $\left(\overline{\mathrm{T}}_{\mathrm{KO}}\right)$ for the period $2000-2015$.

\subsection{Temperature inside Brown Gallery}

It is important to identify whether the method of using the exterior temperature at Knole House, $\overline{\mathrm{T}}_{\mathrm{KO}}$, calculated using the HadCET dataset, $\overline{\mathrm{T}}_{\mathrm{CE}}$, is appropriate to obtain the temperature within the Brown Gallery, $\overline{\mathrm{T}}_{\mathrm{BG}}$. Therefore, Figure 4 compares the daily average temperatures in the Brown Gallery, $\overline{\mathrm{T}}_{\mathrm{BG}}$, calculated using Equations 3 and 4 to the sensor readings from the Brown Gallery. For the sixteen years where data for inside the Brown Gallery are available, Figure 4a shows the results which have the poorest correlation with $\mathrm{R}^{2}=0.80$ (for 2008), and Figure $4 \mathrm{~b}$ shows the results which have the strongest correlation with $\mathrm{R}^{2}=0.96$ (for 2009). Gaps are seen in the results as only days where there is a complete set of hourly data inside the Brown Gallery (either recordings or using Equation 1) have been used in the calculation of the daily average temperature. Averaging the values of $\mathrm{R}^{2}$ over the sixteen years gives $\mathrm{R}^{2}=0.92$, therefore showing very good accuracy between the recordings and model. Previously the linear equation relating outdoor temperature to indoor temperature has been considered as a first-level approximation and it is argued that a more complex model is required in order to capture the daily hysteresis cycles [10]. 
However, the agreement between the model and temperature readings suggests that the hysteresis effect for the Brown Gallery is small and justifies the use of the simple linear transfer function.

(a) 2008

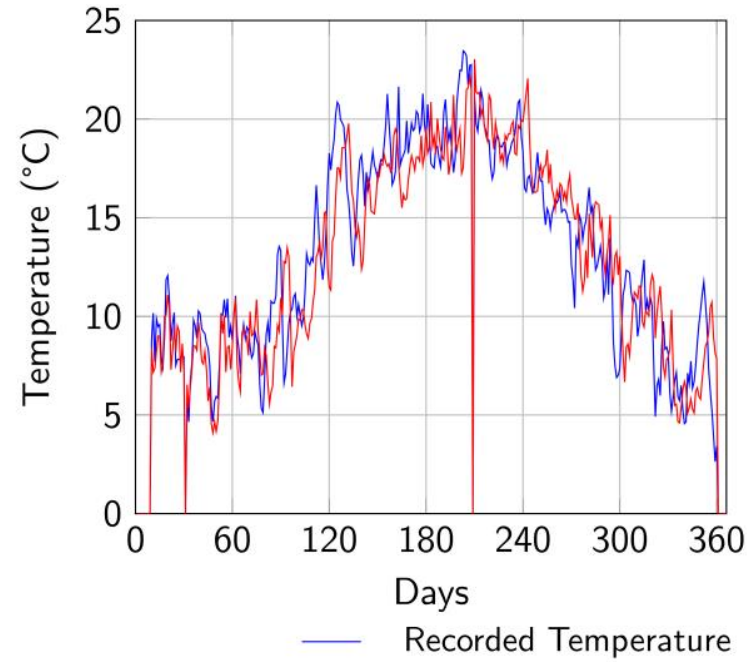

(b) 2009

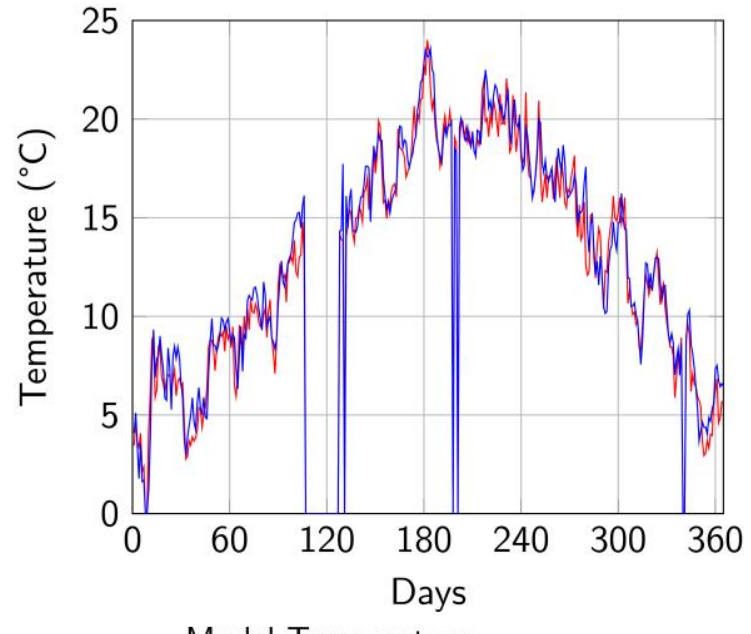

- Model Temperature

Figure 4: Comparison of daily average temperature in the Brown Gallery from recordings and using the relationship between the Central England temperatures. (a) 2008. (b) 2009. The worst and best value of $\mathrm{R}^{2}$, respectively.

The coefficients, $n_{i}$ and $p_{i}$ with $i=1-12$, for the monthly transfer function between the Brown Gallery and exterior at Knole House in Equation 4 are given in Appendix B in Table B2.

The HadCET daily minimum and maximum temperatures are available from 1878 - 2015 (see Table 1), meaning the previous relationship can be used to calculate the daily minimum and maximum temperatures, $\widetilde{\mathrm{T}}_{\mathrm{BG}}$ and $\widehat{\mathrm{T}}_{\mathrm{BG}}$ respectively, in the Brown Gallery from $1878-2015$. $\mathrm{A}$ 10,000 term Fourier series of the form in Equation 5 can be fitted to the results, giving $\mathrm{R}^{2}=0.97$ for the minimum temperatures and $\mathrm{R}^{2}=0.98$ for the maximum temperatures.

The Fourier series for the daily minimum and maximum temperatures in the period $1878-2015$ can be used to extrapolate backwards to identify the daily minimum and maximum temperatures in the Brown Gallery from 1659 - 2015. As previously mentioned, as the daily average temperature (1772 - 1877) and monthly average temperature (1659 - 1771) in Central England are known, correction factors can be applied to the Fourier series to increase the accuracy of the model in these periods, details of which are shown in Appendix A.

As no Central England temperatures are available from 1605 - 1658 (see Table 1), it is not possible to apply a correction factor to the temperatures in this period. Therefore the minimum and maximum data for 1659 - 2015 are fitted with a Fourier series and it is assumed that the Fourier series for the period $1659-2015$ still applies in the region $1605-1658$. For the period $1605-$ 
2015, the minimum daily temperature in the Brown Gallery predicted by the model is $\widetilde{\mathrm{T}}_{\mathrm{BG}}=$ $-7.9^{\circ} \mathrm{C}$, the maximum daily temperature is $\widehat{T}_{\mathrm{BG}}=31.5^{\circ} \mathrm{C}$ and the average daily temperature is $\overline{\mathrm{T}}_{\mathrm{BG}}=12.4^{\circ} \mathrm{C}$. Figure 5 shows the full 10,000 term Fourier series fit to the daily minimum and maximum temperatures in the Brown Gallery for the period $1605-2015$, with $\mathrm{R}^{2}=0.95$ and $\mathrm{R}^{2}=$ 0.96 , respectively.

(a) Daily Minimum Temperature 1605 - 2015

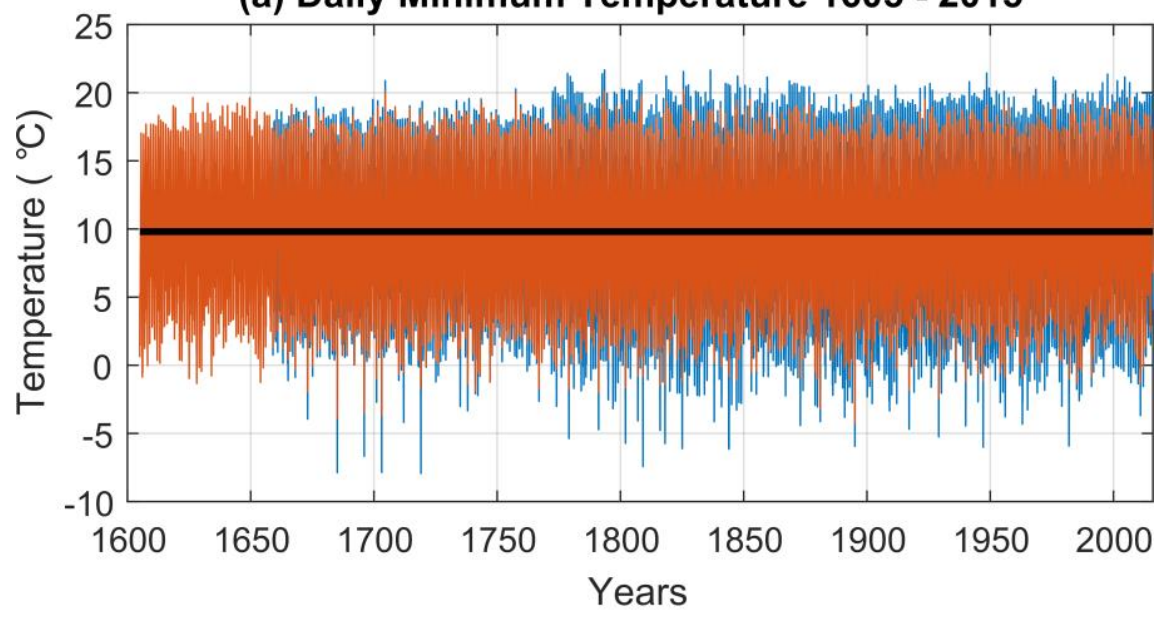

(b) Daily Maximum Temperature 1605 - 2015

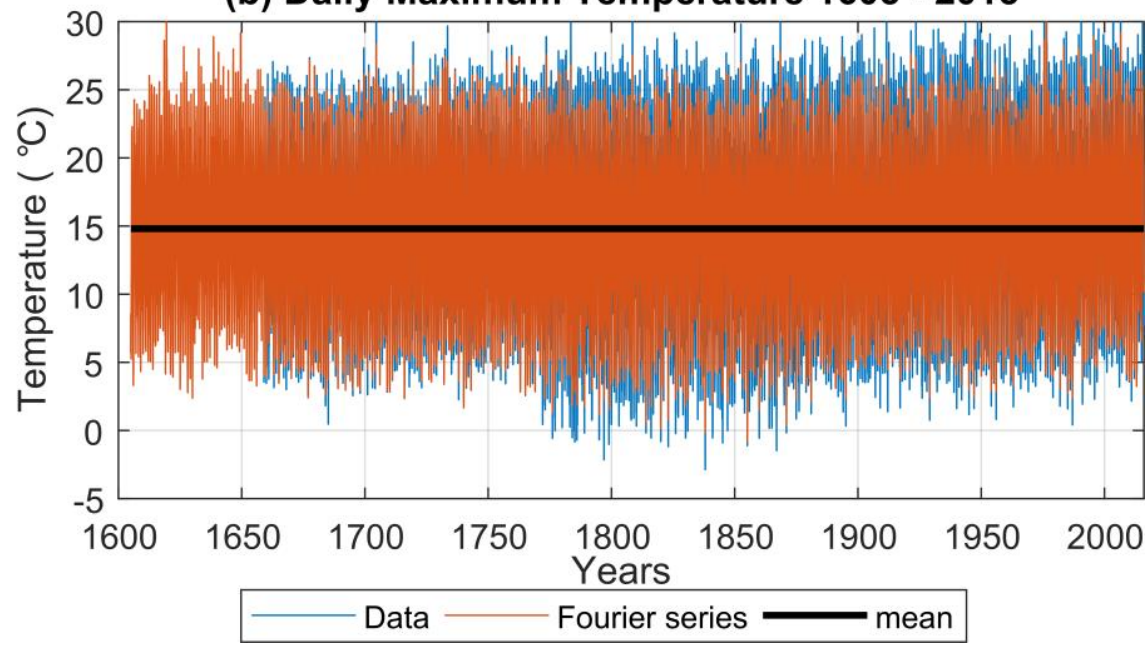

Figure 5: Daily temperature data in the Brown Gallery and Fourier series fit for the period 1605 2015. (a) Minimum temperature $\left(\widetilde{\mathrm{T}}_{\mathrm{BG}}\right)$. (b) Maximum temperature $\left(\widehat{\mathrm{T}}_{\mathrm{BG}}\right)$.

\subsection{Relative humidity inside Brown Gallery}

The daily minimum, $\widetilde{\mathrm{T}}_{\mathrm{BG}}$, and maximum, $\widehat{\mathrm{T}}_{\mathrm{BG}}$, temperatures in the Brown Gallery have been identified for the period 1605 - 2015, meaning that the corresponding maximum, $\widehat{\mathrm{RH}}$, and minimum , $\overline{\mathrm{RH}}$, relative humidity in the Brown Gallery can be obtained, respectively, using the method in Section 3.5. 
Figure 6 shows the daily minimum and maximum relative humidity in the Brown Gallery for the period $1605-2015$. The minimum daily relative humidity in the Brown Gallery predicted by the model is $\overline{\mathrm{RH}}=10.4 \%$, the maximum daily relative humidity is $\widehat{\mathrm{RH}}=100 \%$ and average daily relative humidity $\overline{\mathrm{RH}}=65.2 \%$.
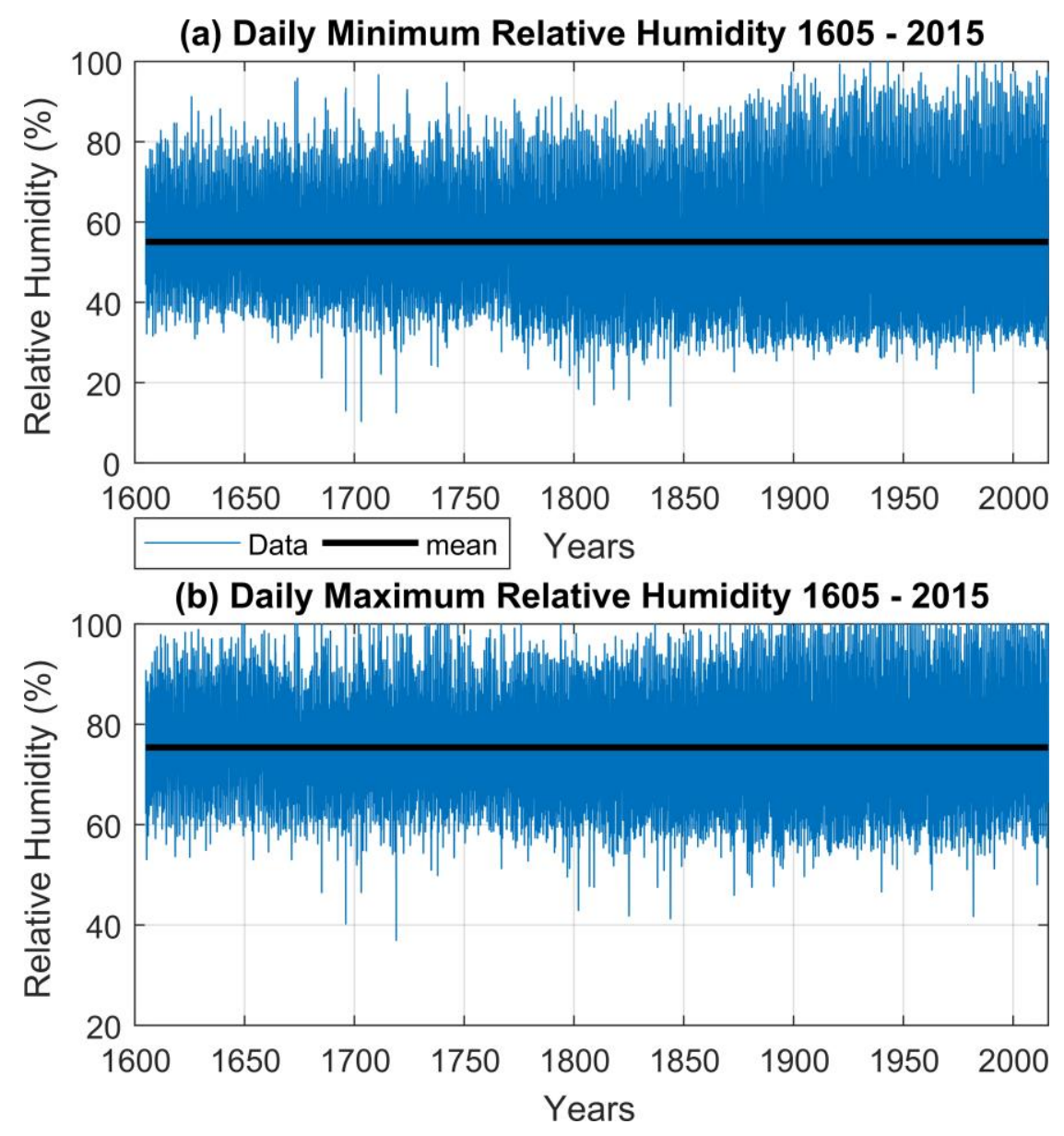

Figure 6: Daily relative humidity data in the Brown Gallery for the period 1605 - 2015. (a) Minimum RH ( $\widetilde{\mathrm{RH}})$. (b) Maximum RH $(\widehat{\mathrm{RH}})$.

Figure 7 shows the daily average temperatures and relative humidity in the Brown Gallery for the period $1605-2015$. 
(a) Daily Average Temperature 1605 - 2015

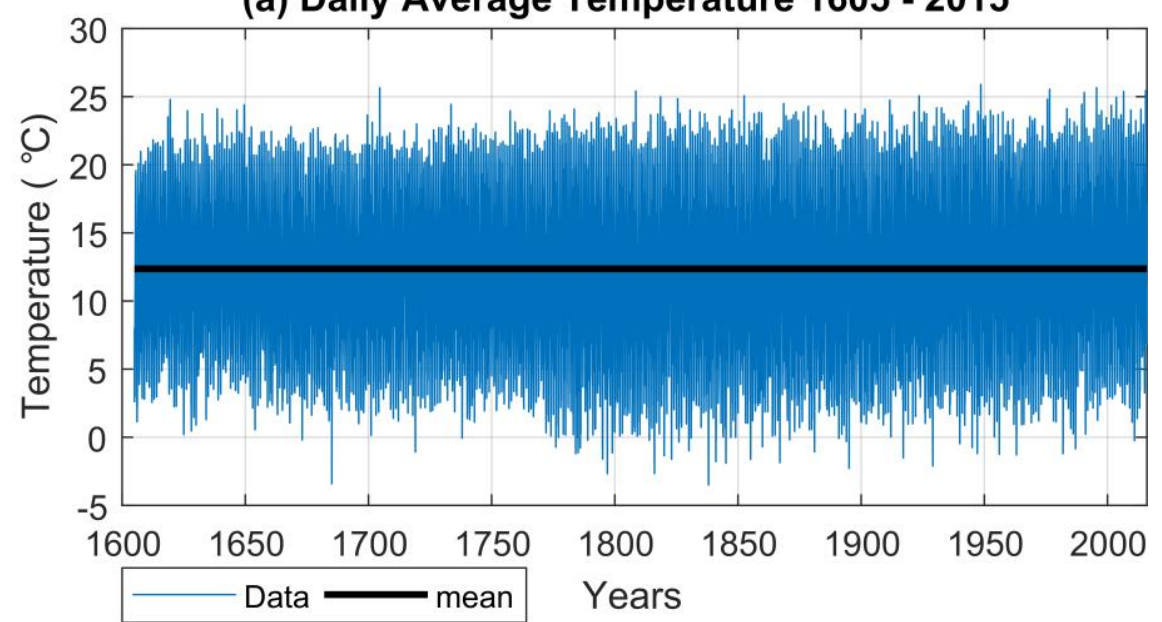

(b) Daily Average Relative Humidity 1605 - 2015

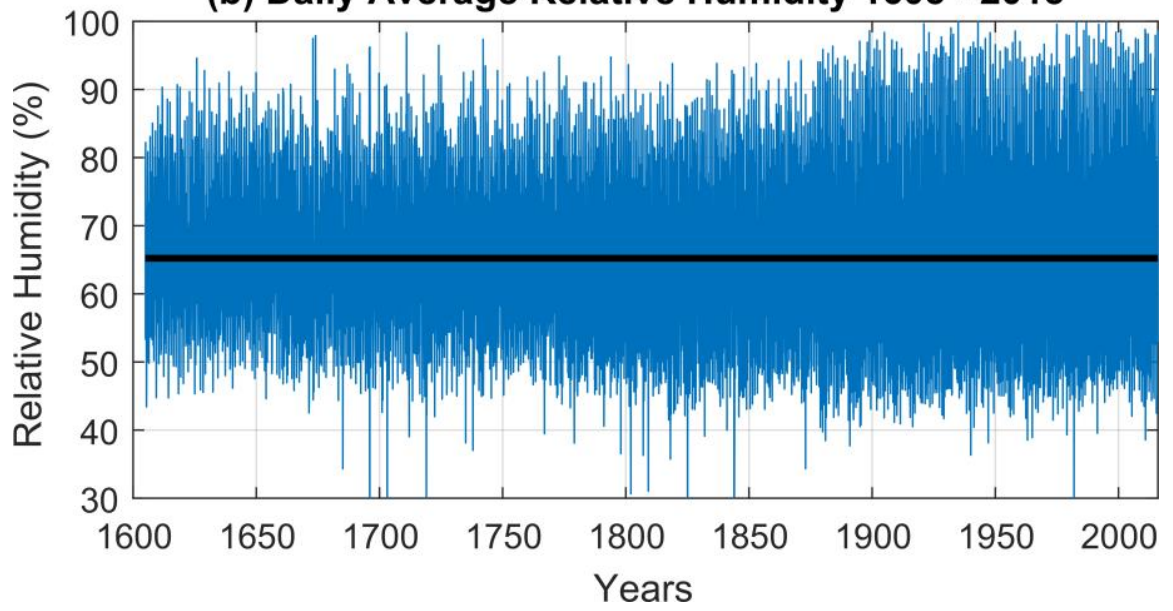

Figure 7: Daily average data in the Brown Gallery for the period 1605 - 2015. (a) Temperature.

(b) Relative humidity.

From Figure 5, 6 and 7 the temperatures and relative humidity appear to be less variable in the past. A cause of this could be climate change allowing the possibility of more extreme temperatures (daily minimum and daily maximum), which would increase the temperature range in a day and the variability over time. As relative humidity is coupled to the temperature then as the temperature variability increases, consequently so will the relative humidity.

Now that the daily minimum, maximum and average temperatures and relative humidity in the Brown Gallery are known for the period 1605 - 2015, a Fourier transform can be performed on the data to identify the main frequencies that the paintings have been exposed to in the gallery over the 411 year period. Figure 8 shows the dominant amplitudes in the frequency spectrum when a Fourier transform is performed on the daily average temperatures and $\mathrm{RH}$ data in the Brown Gallery over the lifetime that the paintings have been on display at Knole House $(\sim 1605-2015)$. When compared to Figure 1a the results of the temperature Fourier transform in Figure $8 \mathrm{a}$ are independent as these are obtained by first converting the minimum and maximum temperatures 
from HadCET to values within the Brown Gallery for 1878 - 1999 and then combining these with the minimum and maximum temperatures from the instrument measurements for $2000-2015$. After fitting the minimum and maximum temperatures for the period 1878 - 2015 with a Fourier series, backwards extrapolation obtains temperatures back to 1659. After correcting the temperatures with daily averages (see Appendix A.1) and monthly averages (see Appendix A.2) the minimum and maximum temperatures are again fitted with a Fourier series to obtain temperatures for the final period $(1605$ - 1658) and a Fourier transform is then performed on these results. As Figure $8 \mathrm{~b}$ was not obtained using backward extrapolation of the RH but through the method in Section 3.5 using the dew point temperature, it is important to confirm that the main frequencies expected are present.

(a) Temperature

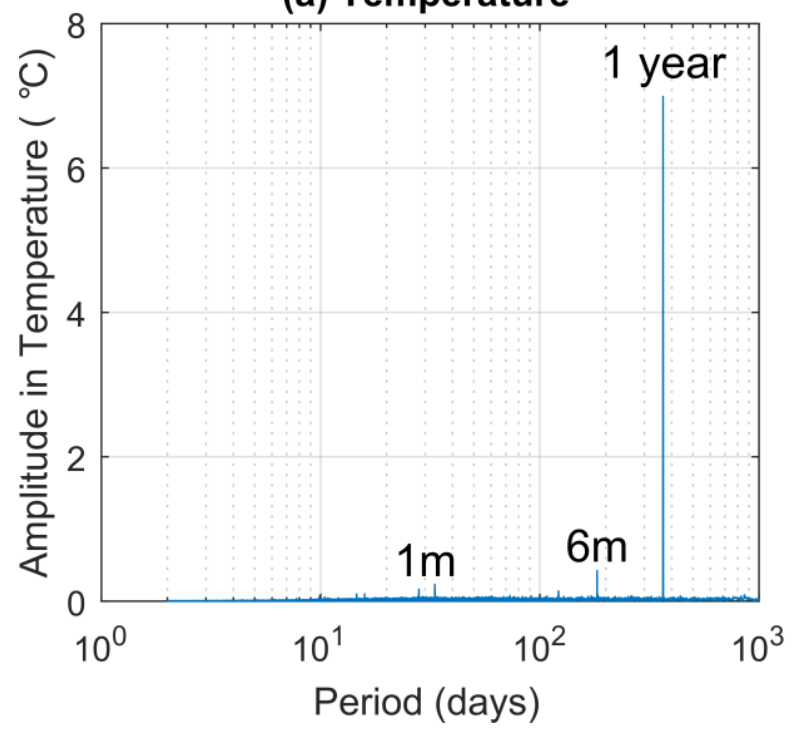

(b) Relative Humidity

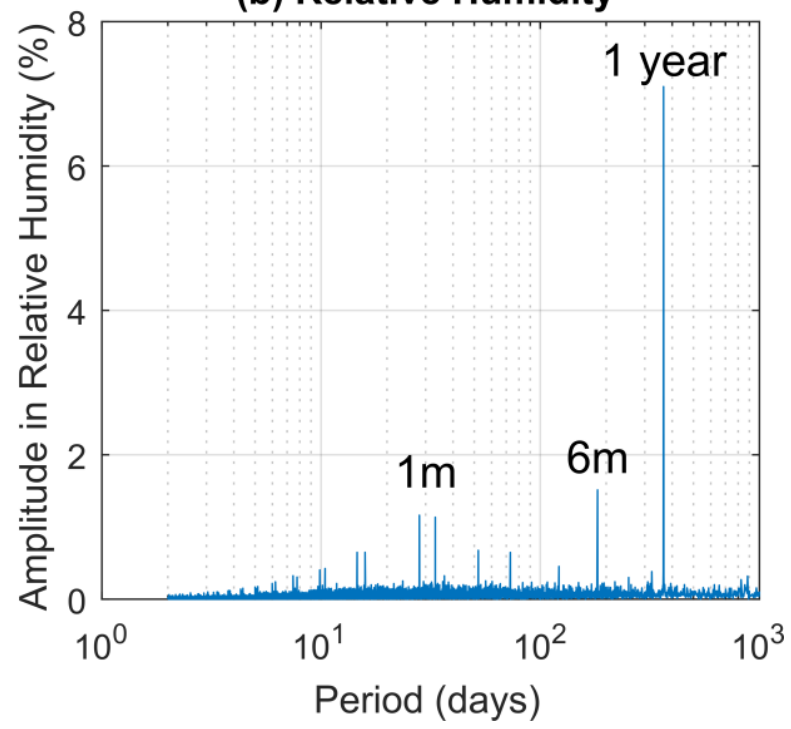

Figure 8: Frequency spectrum for the daily average temperatures and relative humidity in the Brown Gallery after Fourier transform (a) Temperature (b) Relative humidity.

Similar to Figure 1, the largest amplitude in the frequency spectrum for both the temperature and relative humidity corresponds to a period of one year. The other main frequencies observed in the model coincide with periods of six months and one month. Unfortunately due to the sample rate of the temperature and $\mathrm{RH}$ model being daily, it is not possible to obtain amplitudes for periods less than two days. Table 2 shows the three main amplitudes in the frequency spectrum when a Fourier transform is performed on the daily minimum, daily maximum and daily average temperatures and relative humidity in the Brown Gallery for the period $1605-2015$. 
Table 2: Main amplitudes in the frequency spectrum for the Brown Gallery temperature and relative humidity model for $1605-2015$.

\begin{tabular}{|c|c|c|c|c|c|c|}
\hline & \multicolumn{3}{|c|}{ Amplitude in Temperature $\left({ }^{\circ} \mathrm{C}\right)$} & \multicolumn{3}{c|}{ Amplitude in Relative Humidity (\%) } \\
\hline Period (month) & Daily Min. & Daily Max. & Daily Av. & Daily Min. & Daily Max. & Daily Av. \\
\hline 1 & 0.24 & 0.23 & 0.23 & 1.01 & 1.36 & 1.16 \\
\hline 6 & 0.61 & 0.33 & 0.42 & 1.26 & 2.62 & 1.51 \\
\hline 12 & 6.32 & 7.68 & 6.99 & 8.85 & 5.35 & 7.09 \\
\hline
\end{tabular}

\section{Conclusions}

A method has been presented to obtain the temperature and associated relative humidity in the Brown Gallery, located at Knole House, Kent from the beginning of the $17^{\text {th }}$ Century to $21^{\text {st }}$ Century. The temperature in the Brown Gallery is obtained by establishing two relationships between: (1) the temperature in Central England and outside Knole House, and (2) outside Knole house and inside the Brown Gallery. A linear transfer function has been used to obtain the internal temperature in the gallery from the outside temperature. When comparing the accuracy of the model for each of the 16 years that daily average temperature readings are available for the Brown Gallery the average $\mathrm{R}^{2}=0.92$, showing how powerful the simple technique is. A more complex approach such as building simulations may ascertain more accurate results, however the high development costs with such a method propose the question as to whether the small increase is worthwhile. Fitting the Central England temperature data for years 1878 - 2015 with a Fourier series, it is possible to extrapolate backwards to identify the daily minimum $\left(\widetilde{\mathrm{T}}_{\mathrm{BG}}\right)$ and maximum $\left(\widehat{T}_{\mathrm{BG}}\right)$ temperatures that the paintings have been exposed to in the gallery since they were created in approx. 1605. Furthermore, correction factors are applied to the Fourier series temperatures, derived using daily and monthly temperature averages from HadCET which increase the accuracy of the model.

The daily minimum $(\widetilde{\mathrm{RH}})$ and maximum $(\widehat{\mathrm{RH}})$ relative humidity in the Brown Gallery are obtained in two parts. Initially the daily actual vapour pressure in air $\left(\mathrm{e}_{\mathrm{a}}\right)$ is calculated using the dew point temperature at Knole $\left(\mathrm{T}_{\mathrm{dew}}\right)$, obtained by subtracting a monthly-dependent constant $\left(\mathrm{v}_{\mathrm{i}}\right)$ from the daily minimum temperature at Knole $\left(\widetilde{\mathrm{T}}_{\mathrm{KO}}\right)$. It is then assumed that the change in relative humidity in the gallery is a result of the temperature cycle varying the saturation vapour pressure of air. Therefore the daily minimum $\left(\widetilde{\mathrm{T}}_{\mathrm{BG}}\right)$ and maximum $\left(\widehat{\mathrm{T}}_{\mathrm{BG}}\right)$ temperatures in the Brown Gallery are used to calculate the saturation vapour pressure $\left(\mathrm{e}_{\mathrm{s}}\right)$ at each temperature and thus daily minimum $(\widetilde{\mathrm{RH}})$ and maximum $(\widehat{\mathrm{RH}})$ relative humidity are obtained for the period $1605-2015$. 
When considering the present work, the main novelties are: (1) for the first time the historic environment in the Brown Gallery at Knole House has been reconstructed for the period 1605 2015, whereas previous studies have focused on different galleries within Knole House (Leicester gallery and Cartoon Gallery) and been concerned with a different period of time (1780 - 2100) [6]-[8], (2) the main frequencies that the paintings have been subjected to over their lifetime in the Brown Gallery, as a result of the temperature and relative humidity cycles have been identified by performing a Fourier transform on the data, (3) for the first time a Fourier series has been used to extrapolate the temperatures in the Brown Gallery back in time, with a unique method to increase the accuracy of the predicted temperatures using correction factors derived from daily and monthly temperature averages obtained from HadCET [16] and finally, (4) for the first time the method [22], [24] to obtain the RH by calculating the daily actual vapour pressure of air from the dew point temperature has been applied to calculate the minimum and maximum $\mathrm{RH}$ of an unheated room.

The data presented in this work is crucial in the study of environmentally-induced low-cycle fatigue in panel paintings as it provides the past environment that the paintings within the gallery have been subjected to. The frequency spectrum obtained from the Fourier transform can be implemented in fatigue testing when mechanical loading simulates the strain fluctuations in the paintings due to changes in temperature and relative humidity, allowing the validation of low-cycle fatigue finite element models where the temperature and relative humidity cycles can be directly applied to the models for the two predominant crack types seen within the paintings (interfacial and through-thickness channelling cracks). 


\section{Appendix A}

\section{A.1. Daily correction factor for period $1772-1877$}

The daily average temperature outside Knole House, $\overline{\mathrm{T}}_{\mathrm{KO}}$, for the period $1772-1877$ is calculated using the daily average temperature in Central England, $\overline{\mathrm{T}}_{\mathrm{CE}}$, and Equation 3 from Section 3.3. The Equation 4 in Section 3.4 is then used to obtain the daily average temperature in the Brown Gallery $\left(\overline{\mathrm{T}}_{\mathrm{BG}}\right)$ for the same period. To increase the accuracy of the daily minimum $\left(\widetilde{\mathrm{T}}_{\mathrm{BG}-\mathrm{f}}\right)$ and maximum $\left(\widehat{\mathrm{T}}_{\mathrm{BG}-\mathrm{f}}\right)$ temperatures, where the subscript $-\mathrm{f}$ signifies the temperature was obtained from the Fourier series, it is possible to derive a correction factor $\left(\mathrm{C}_{\mathrm{d}}\right)$ for each day in the period $1772-1877$ as follows

$$
\frac{\mathrm{C}_{\mathrm{d}}}{2}\left(\widetilde{\mathrm{T}}_{\mathrm{BG}-\mathrm{f}}+\widehat{\mathrm{T}}_{\mathrm{BG}-\mathrm{f}}\right)=\overline{\mathrm{T}}_{\mathrm{BG}}
$$

Once the daily correction factor, $\mathrm{C}_{\mathrm{d}}$ is known, the daily minimum and maximum temperatures are calculated

$$
\begin{aligned}
& \widetilde{\mathrm{T}}_{\mathrm{BG}}=\mathrm{C}_{\mathrm{d}} \widetilde{\mathrm{T}}_{\mathrm{BG}-\mathrm{f}} \\
& \widehat{\mathrm{T}}_{\mathrm{BG}}=\mathrm{C}_{\mathrm{d}} \widehat{\mathrm{T}}_{\mathrm{BG}-\mathrm{f}}
\end{aligned}
$$

Unfortunately, as the Fourier series does not perfectly fit the data, it is possible for $\widetilde{\mathrm{T}}_{\mathrm{BG}-\mathrm{f}}>$ $\widehat{T}_{B G-f}$. When this occurs, the results are inverted to ensure that $\widetilde{T}_{B G} \leq \widehat{T}_{B G}$. Similarly, when $C_{d}$ is negative and $\left(\widetilde{\mathrm{T}}_{\mathrm{BG}-\mathrm{f}}<0\right.$ and $\left.\widehat{\mathrm{T}}_{\mathrm{BG}-\mathrm{f}}>0\right)$ or $\left(\widetilde{\mathrm{T}}_{\mathrm{BG}-\mathrm{f}}<0\right.$ and $\left.\widehat{\mathrm{T}}_{\mathrm{BG}-\mathrm{f}}<0\right)$ or $\left(\widetilde{\mathrm{T}}_{\mathrm{BG}-\mathrm{f}}>0\right.$ and $\widehat{\mathrm{T}}_{\mathrm{BG}-\mathrm{f}}>0$ ), the Brown Gallery minimum and maximum temperatures are obtained using $\widetilde{\mathrm{T}}_{\mathrm{BG}}=$

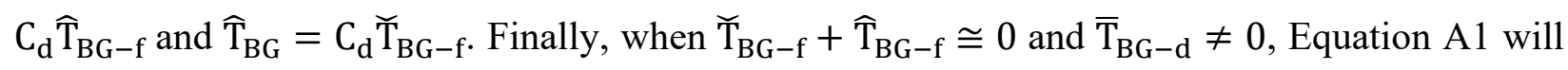
give $C_{d} \gg 1$ or $C_{d} \ll-1$. In this case the resulting minimum and maximum temperatures are extremely unrealistic. Therefore, a range for $C_{d}$ is obtained by considering the minimum and maximum temperatures in the period 1878 - 2015 and identifying that the maximum temperature range for a day $\left(\widehat{\mathrm{T}}_{\mathrm{BG}}-\widetilde{\mathrm{T}}_{\mathrm{BG}}\right)$ is $16.4^{\circ} \mathrm{C}$. Using this constraint in the calculation of $\mathrm{C}_{\mathrm{d}}$ gives $-1.6 \leq$ $\mathrm{C}_{\mathrm{d}} \leq 1.6$. The average value of the daily correction factor $\overline{\mathrm{C}}_{\mathrm{d}}=0.98$.

\section{A.2. Monthly correction factor for period $1659-1771$}

Similarly, for the period 1659 - 1771, a correction factor, $\mathrm{C}_{\mathrm{m}}$, can be derived from HadCET to improve the accuracy of the daily minimum and maximum temperatures in the Brown Gallery predicted by the Fourier Series, $\breve{\mathrm{T}}_{\mathrm{BG}-\mathrm{f}}$ and $\widehat{\mathrm{T}}_{\mathrm{BG}-\mathrm{f}}$ respectively. However, the HadCET daily average temperatures $\left(\bar{T}_{\mathrm{CE}}\right)$ are not available in this period (see Table 1), but monthly average 
temperatures ( $-\mathrm{m}$ subscript) are. This means that the monthly average temperatures in Central England $\left(\overline{\mathrm{T}}_{\mathrm{CE}-\mathrm{m}}\right)$ can be converted to the monthly average temperatures in the Brown Gallery $\left(\bar{T}_{\mathrm{BG}-\mathrm{m}}\right)$ and used to calibrate the monthly correction factor $\left(\mathrm{C}_{\mathrm{m}}\right)$ in this period according to Equation A4.

$$
\frac{\mathrm{C}_{\mathrm{m}}}{2 \mathrm{M}} \sum_{\mathrm{i}=1}^{\mathrm{M}}\left(\widetilde{\mathrm{T}}_{\mathrm{BG}-\mathrm{f}}+\widehat{\mathrm{T}}_{\mathrm{BG}-\mathrm{f}}\right)_{\mathrm{i}}=\overline{\mathrm{T}}_{\mathrm{BG}-\mathrm{m}}
$$

where $\mathrm{M}$ is the number of days in the month. These correction factors can then be applied to the minimum and maximum temperatures obtained from the Fourier series in the given period. The average value of the monthly correction factor $\overline{\mathrm{C}}_{\mathrm{m}}=0.97$. 


\section{Appendix B}

\section{B.1. Transfer function coefficients for Brown Gallery and Cartoon Gallery}

Coefficients for the monthly relationship between the Brown Gallery and Cartoon Gallery from Equations 1 and 2 in Section 3.2 are shown in Table B1.

Table B1: Coefficients for the monthly relationship between the Brown Gallery and Cartoon Gallery from Equations 1 and 2 in Section 3.2.

\begin{tabular}{|c|c|c|c|c|c|}
\hline \multirow{2}{*}{$\mathbf{i}$} & \multirow{2}{*}{ Month } & \multicolumn{2}{|c|}{ Temperature } & \multicolumn{2}{|c|}{ RH } \\
\cline { 3 - 6 } & & $\mathbf{a}_{\mathbf{i}}$ & $\mathbf{b}_{\mathbf{i}}$ & $\mathbf{e}_{\mathbf{i}}$ & $\mathbf{g}_{\mathbf{i}}$ \\
\hline 1 & January & 0.857 & 0.852 & 0.617 & 30.397 \\
\hline 2 & February & 0.865 & 0.389 & 0.644 & 27.802 \\
\hline 3 & March & 0.938 & 0.146 & 0.627 & 28.373 \\
\hline 4 & April & 0.919 & 0.710 & 0.689 & 20.843 \\
\hline 5 & May & 0.968 & 0.675 & 0.660 & 21.112 \\
\hline 6 & June & 1.066 & -1.062 & 0.896 & 6.089 \\
\hline 7 & July & 0.877 & 2.492 & 0.763 & 14.536 \\
\hline 8 & August & 0.999 & -0.194 & 0.826 & 11.489 \\
\hline 9 & September & 0.975 & 0.048 & 0.758 & 17.040 \\
\hline 10 & October & 1.035 & -0.774 & 0.712 & 21.078 \\
\hline 11 & November & 0.959 & 0.239 & 0.575 & 32.783 \\
\hline 12 & December & 0.908 & 0.568 & 0.522 & 37.506 \\
\hline
\end{tabular}

Coefficients for the monthly relationship between the Brown Gallery and exterior at Knole House from Equation 4 in Section 3.4 are given in Table B2. 
Table B2: Coefficients for the monthly temperature relationship between the Brown Gallery and exterior at Knole House from Equation 4 in Section 3.4.

\begin{tabular}{|c|c|c|c|}
\hline \multirow{2}{*}{$\mathbf{i}$} & \multirow{2}{*}{ Month } & \multicolumn{2}{|c|}{ Temperature } \\
\cline { 3 - 4 } & & $\mathbf{n}_{\mathbf{i}}$ & $\mathbf{p}_{\mathbf{i}}$ \\
\hline 1 & January & 0.590 & 3.882 \\
\hline 2 & February & 0.652 & 3.330 \\
\hline 3 & March & 0.717 & 3.713 \\
\hline 4 & April & 0.715 & 4.970 \\
\hline 5 & May & 0.638 & 6.925 \\
\hline 6 & June & 0.634 & 8.159 \\
\hline 7 & July & 0.652 & 8.167 \\
\hline 8 & August & 0.658 & 7.977 \\
\hline 9 & September & 0.668 & 6.714 \\
\hline 10 & October & 0.694 & 5.326 \\
\hline 11 & November & 0.589 & 5.043 \\
\hline 12 & December & 0.595 & 4.081 \\
\hline
\end{tabular}

Constants for the monthly relationship between the minimum temperature at Knole $\left(\widetilde{\mathrm{T}}_{\mathrm{KO}}\right)$ and the dew point temperature $\left(\mathrm{T}_{\mathrm{dew}}\right)$ in Section 3.5 are given in Table B3.

\section{B.3. Dew point temperature calculation monthly-dependent constants}

Table B3: Coefficients used in Equation 10 for the monthly temperature relationship between the minimum temperature outside Knole House $\left(\widetilde{\mathrm{T}}_{\mathrm{KO}}\right)$ and the dew point temperature $\left(\mathrm{T}_{\text {dew }}\right)$.

\begin{tabular}{|c|c|c|}
\hline $\mathbf{i}$ & Month & $\mathbf{v}_{\mathbf{i}}$ \\
\hline 1 & January & 0.000 \\
\hline 2 & February & 0.119 \\
\hline 3 & March & 0.282 \\
\hline 4 & April & 0.634 \\
\hline 5 & May & 1.067 \\
\hline 6 & June & 1.962 \\
\hline 7 & July & 1.712 \\
\hline 8 & August & 1.318 \\
\hline 9 & September & 0.635 \\
\hline 10 & October & 0.147 \\
\hline 11 & November & 0.382 \\
\hline 12 & December & 0.000 \\
\hline
\end{tabular}


The monthly correction constants $\left(v_{i}\right)$ for the dew point temperature show a similar trend to Upreti et al. [22], with summer months (May to August) requiring a greater correction to the dew point temperature $\left(\mathrm{T}_{\mathrm{dew}}\right)$.

\section{Acknowledgements}

The authors would like to thank Nigel Blades, Diana Jaskierny, Christine Sitwell, Knole House, The National Trust and The Courtauld Institute of Art. Funding for this work was provided by the Engineering and Physical Sciences Research Council (EPSRC) under grant reference EP/P003613/1. The source for the Hadley Centre Central England Temperature (HadCET) dataset was www.metoffice.gov.uk/hadobs.

\section{Declarations of interest}

None.

\section{References}

[1] I. Tyers, "The tree-ring analysis of 8 panel paintings from the Historical Portrait Set in the Brown Gallery, Sackville Collection, Knole,” Dendrochronological Consult. Rep. 532, no. August, pp. 1-39, 2012.

[2] S. Tantideeravit, M. N. Charalambides, D. S. Balint, and C. R. T. Young, "Prediction of delamination in multilayer artist paints under low amplitude fatigue loading," Eng. Fract. Mech., vol. 112-113, pp. 41-57, 2013.

[3] M. F. Mecklenburg and C. S. Tumosa, "Mechanical behaviour of paintings subjected to changes in temperature and relative humidity," Art Transp. Stud. Transp. Paint., pp. 173216, 1991.

[4] S. Michalski and M. F. e Mecklenburg, "Paintings: Their response to temperature, relative humidity, shock, and vibration," in International Conference on the Packing and Transportation of Paintings. Art in Transit: Studies in the Transport of Paintings, 1991, pp. $223-248$.

[5] T. Arends, L. Pel, and D. Smeulders, "Moisture penetration in oak during sinusoidal humidity fluctuations studied by NMR,” Constr. Build. Mater., vol. 166, pp. 196-203, 2018.

[6] P. Lankester and P. Brimblecombe, "Future thermohygrometric climate within historic houses," J. Cult. Herit., vol. 13, no. 1, pp. 1-6, 2012.

[7] P. Lankester and P. Brimblecombe, "The impact of future climate on historic interiors," Sci. 
Total Environ., vol. 417-418, pp. 248-254, 2012.

[8] P. Brimblecombe and P. Lankester, "Long-term changes in climate and insect damage in historic houses," Stud. Conserv., vol. 58, no. 1, pp. 13-22, 2013.

[9] Ł. Bratasz, I. Harris, Ł. Lasyk, M. Łukomski, and R. Kozłowski, "Future climate-induced pressures on painted wood," J. Cult. Herit., vol. 13, no. 4, pp. 365-370, 2012.

[10] D. Camuffo, C. Bertolin, A. Bonazzi, F. Campana, and C. Merlo, "Past, present and future effects of climate change on a wooden inlay bookcase cabinet: A new methodology inspired by the novel European Standard EN 15757:2010," J. Cult. Herit., vol. 15, no. 1, pp. 26-35, 2014.

[11] C. Bertolin, D. Camuffo, and I. Bighignoli, "Past reconstruction and future forecast of domains of indoor relative humidity fluctuations calculated according to EN 15757:2010,” Energy Build., vol. 102, pp. 197-206, 2015.

[12] R. Kramer, J. van Schijndel, and H. Schellen, "Inverse modeling of simplified hygrothermal building models to predict and characterize indoor climates," Build. Environ., vol. 68, pp. 87-99, 2013.

[13] J. Leissner, R. Kilian, and L. Kotova, et al., "Climate for culture: Assessing the impact of climate change on the future indoor climate in historic buildings using simulations," Herit. Sci., vol. 3, no. 1, pp. 1-15, 2015.

[14] G. Leijonhufvud, "Making sense of climate risk information: The case of future indoor climate risks in Swedish churches," Clim. Risk Manag., vol. 13, pp. 76-87, 2016.

[15] Z. Huijbregts, H. Schellen, J. van Schijndel, and B. Ankersmit, "Modelling of heat and moisture induced strain to assess the impact of present and historical indoor climate conditions on mechanical degradation of a wooden cabinet," J. Cult. Herit., vol. 16, no. 4, pp. 419-427, 2015.

[16] D. E. Parker, T. P. Legg, and C. K. Folland, "A new daily Central England Temperature Series, 1772-1991,” Int. J. Climatol., vol. 12, pp. 317-342, 1992.

[17] D. Jaskierny, "The classification and categorisation of crack patterns and delamination found on panels in the Brown Gallery of Knole House," Postgraduate diploma in the conservation of easel painting, Thesis, The Courtauld Institute of Art, 2017.

[18] S. Jakieła, U. Bratasz, and R. Kozłowski, "Acoustic Emission for Tracing the Evolution of Damage in Wooden Objects," Stud. Conserv., vol. 52, no. 2, pp. 101-109, 2007.

[19] M. Strojecki, M. Łukomski, L. Krzemień, J. Sobczyk, and Ł. Bratasz, “Acoustic emission monitoring of an eighteenth-century wardrobe to support a strategy for indoor climate management," Stud. Conserv., vol. 59, no. 4, pp. 225-232, 2014. 
[20] C. Daunt, "A Gallery of Fame: The Evidence for a Jacobean Portrait Frieze at Knole," in National Trust Historic Houses \& Collections Annual 2016, APOLLO, 2016, pp. 28-33.

[21] R. Allen, L. Pereira, D. Raes, and M. Smith, "Crop Evapotranspiration - Guidelines for Computing Crop Water Requirements," in FAO Irrigation and drainage paper 56, 1998.

[22] H. Upreti, C. S. P. Ojha, and F. Asce, "Estimation of Relative Humidity and Dew Point Temperature Using Limited Meteorological Data," J. Irrig. Drain. Eng., vol. 143, no. 9, pp. 1-11, 2017.

[23] E. Eccel, "Estimating air humidity from temperature and precipitation measures for modelling applications," R. Meteorol. Soc., vol. 19, pp. 118-128, 2012.

[24] L. N. Gunawardhana, G. A. Al-rawas, and S. Kazama, "An alternative method for predicting relative humidity for climate change studies,” R. Meteorol. Soc., vol. 24, pp. 551-559, 2017.

[25] D. Gaffen and R. Ross, "Climatology and Trends of U . S . Surface Humidity and Temperature," J. Clim., vol. 12, pp. 811-828, 1999. 